\title{
Correction to: Policies for Later-Life Families in a Comparative European Perspective
}

\author{
Pearl A. Dykstra and Maja Djundeva
}

\section{Correction to:}

Chapter 14 in: R. Nieuwenhuis and W. Van Lancker (eds.), The Palgrave Handbook of Family Policy, https://doi.org/10.1007/978-3-030-54618-2_14

The original version of this chapter was published with incorrect information in Table 14.1, which has been updated now. 


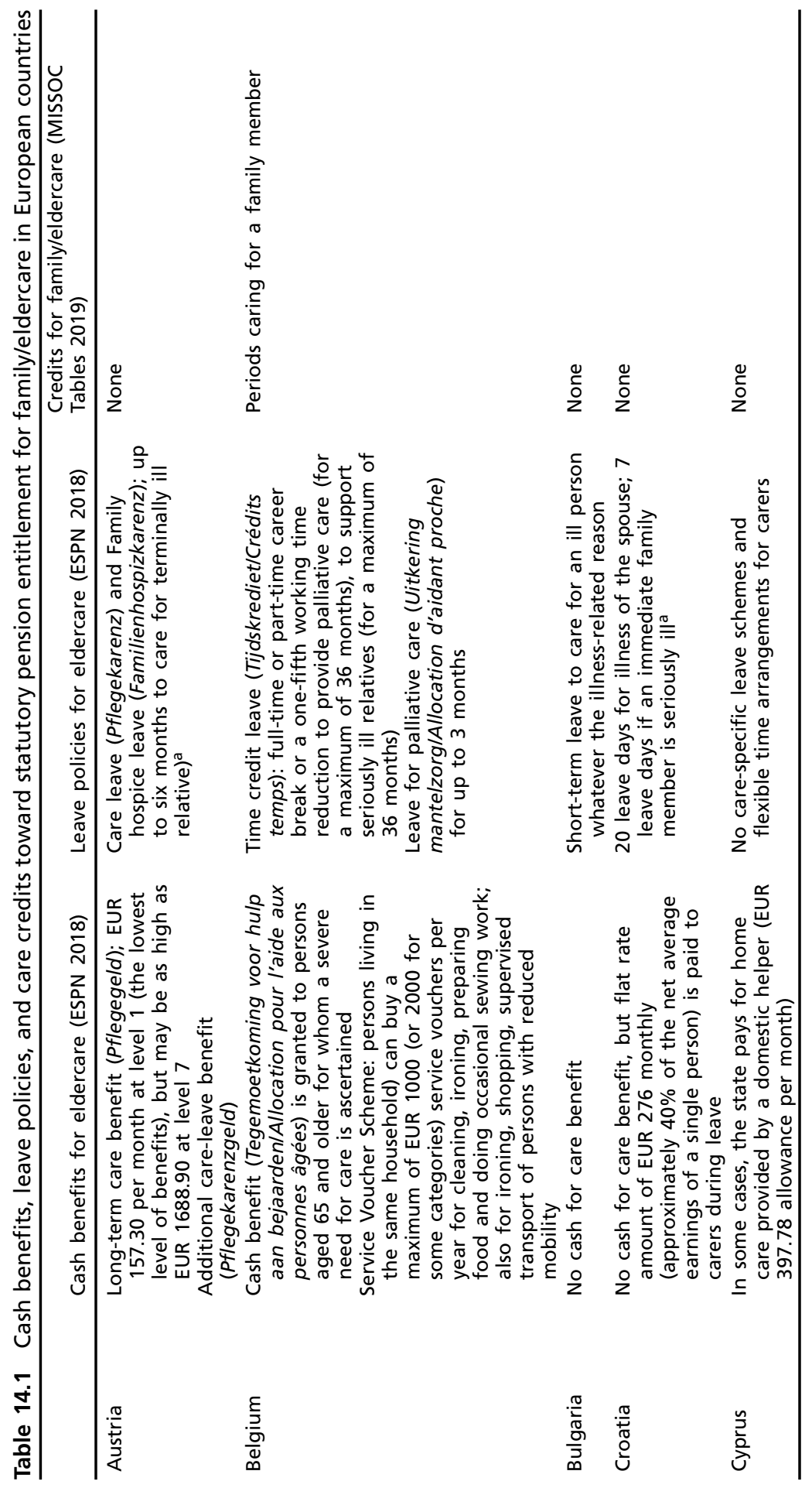




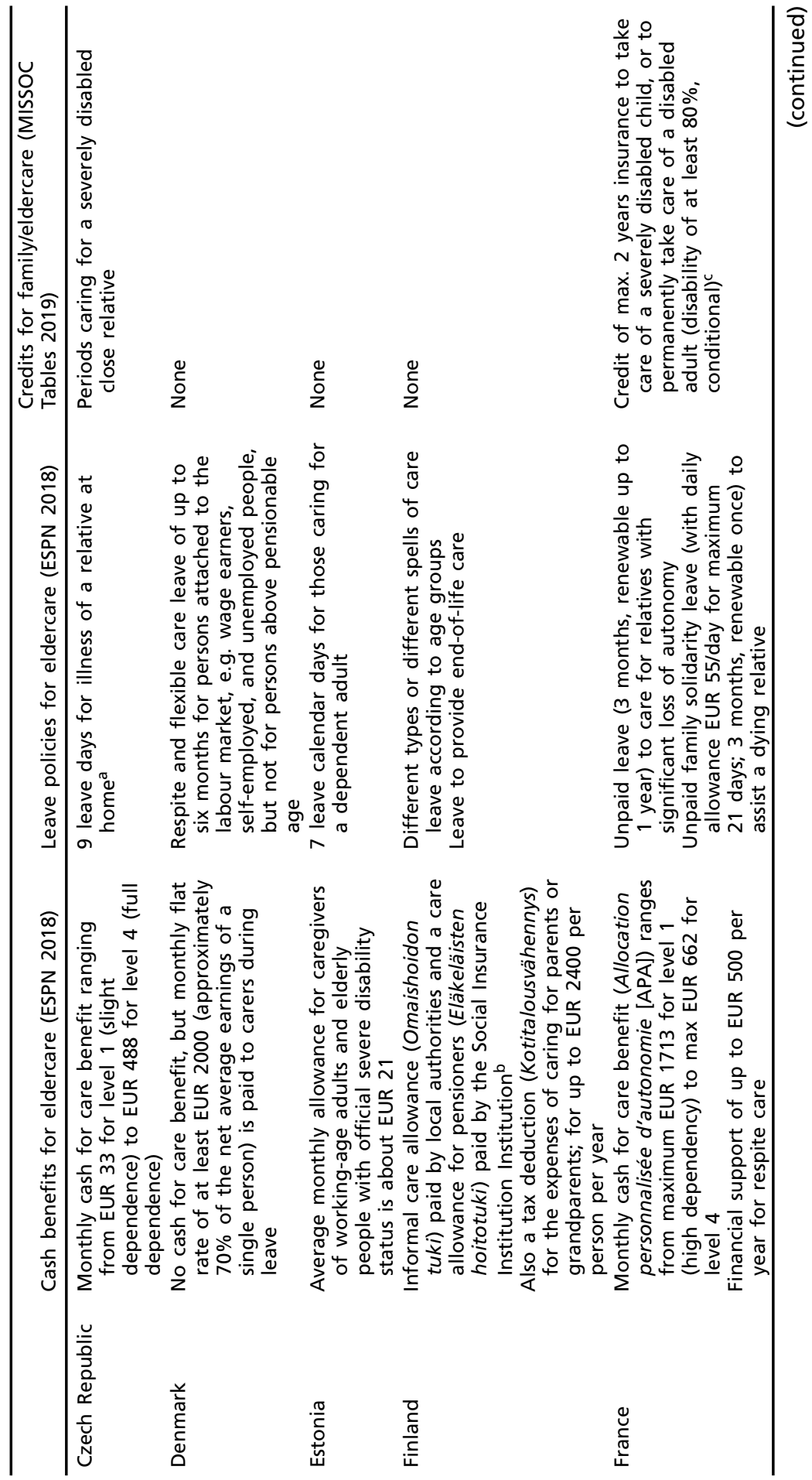




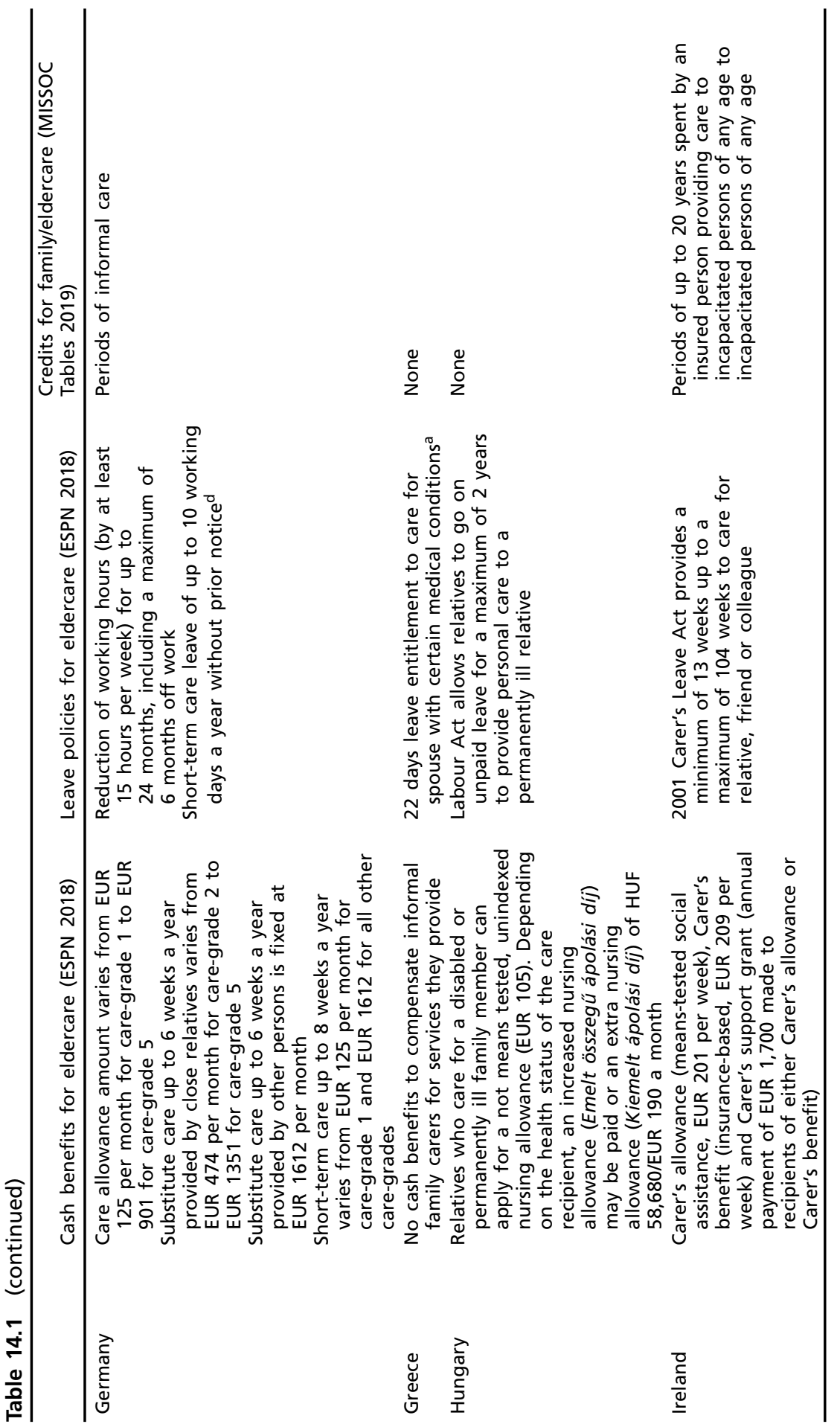




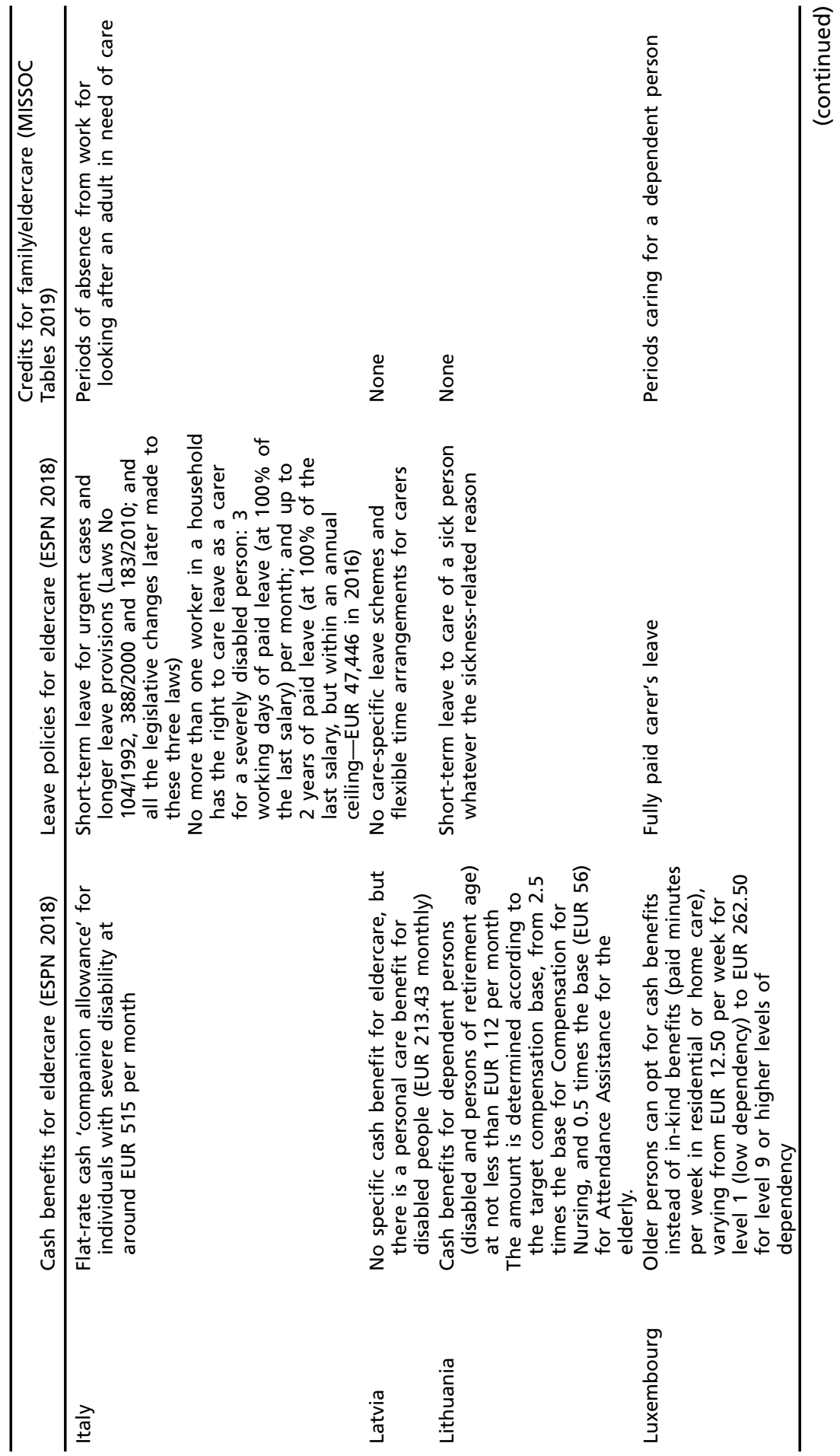




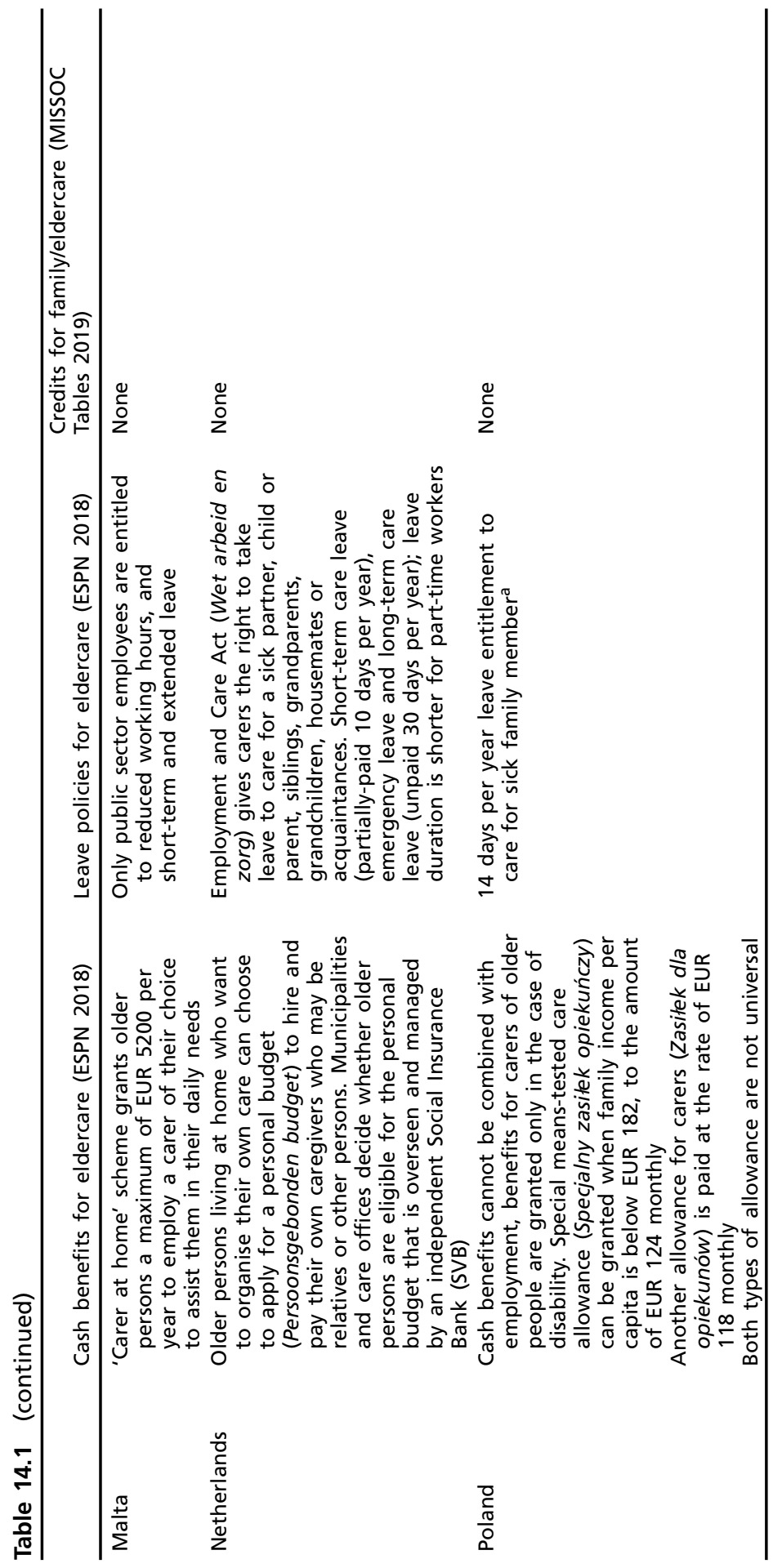




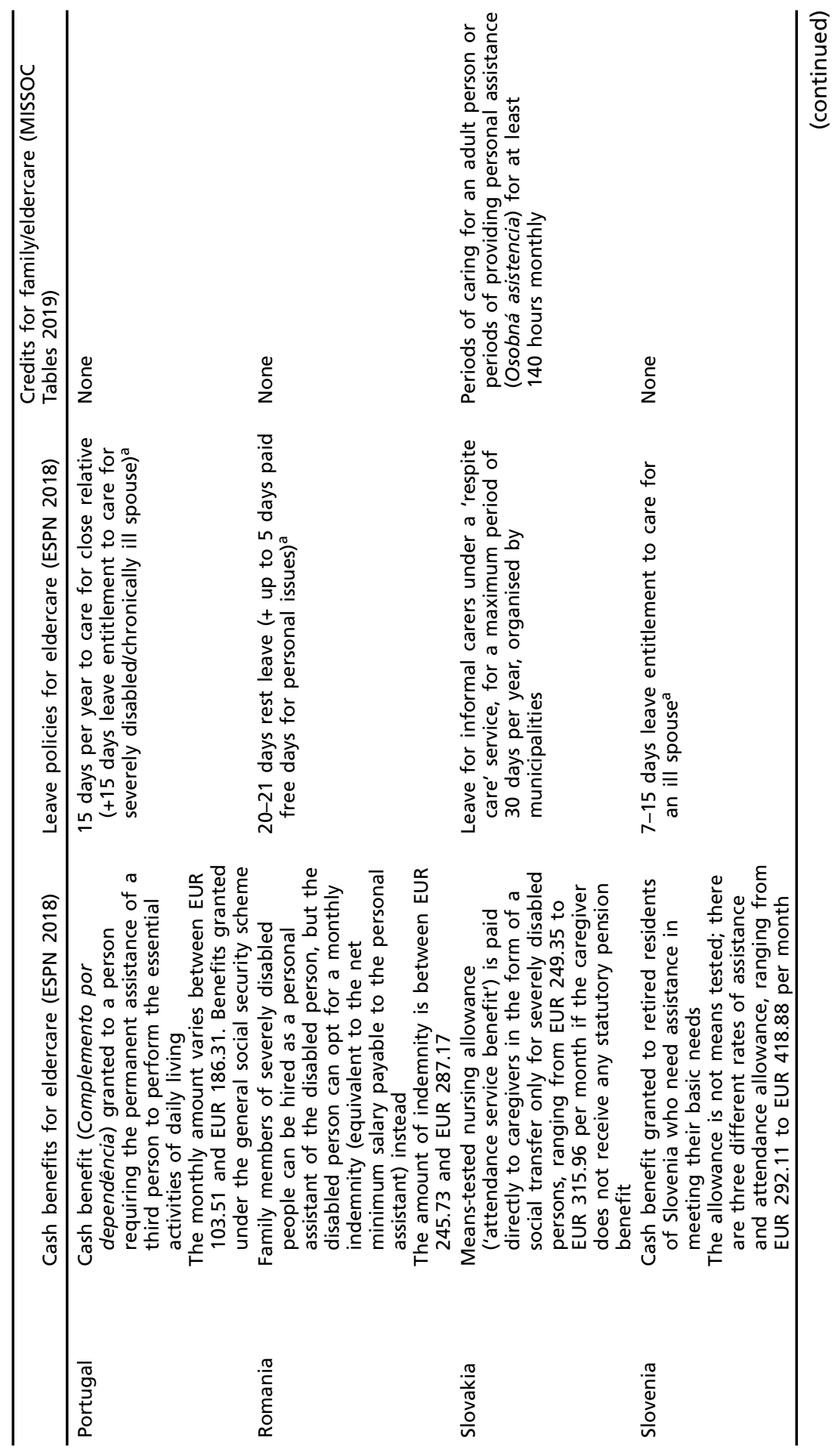




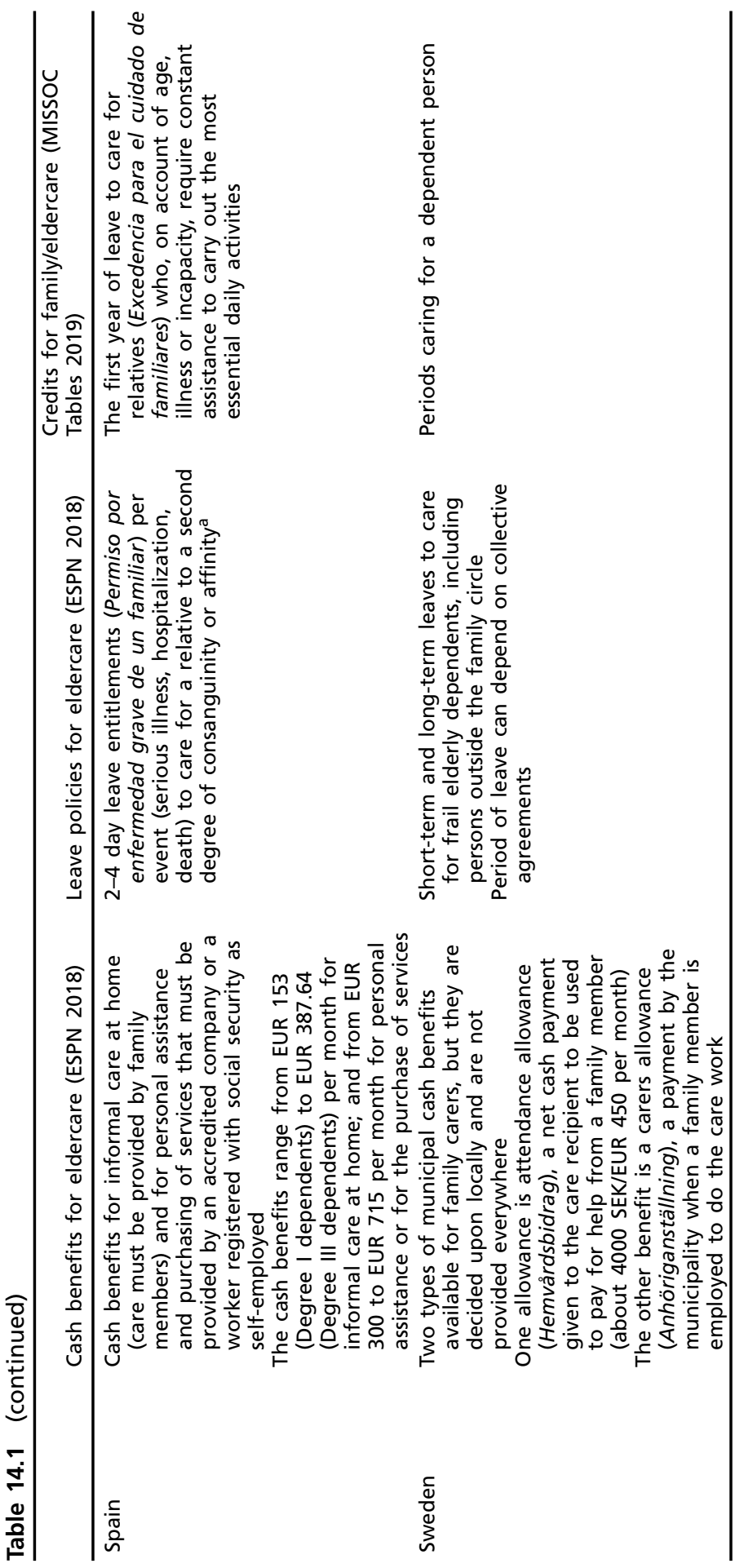




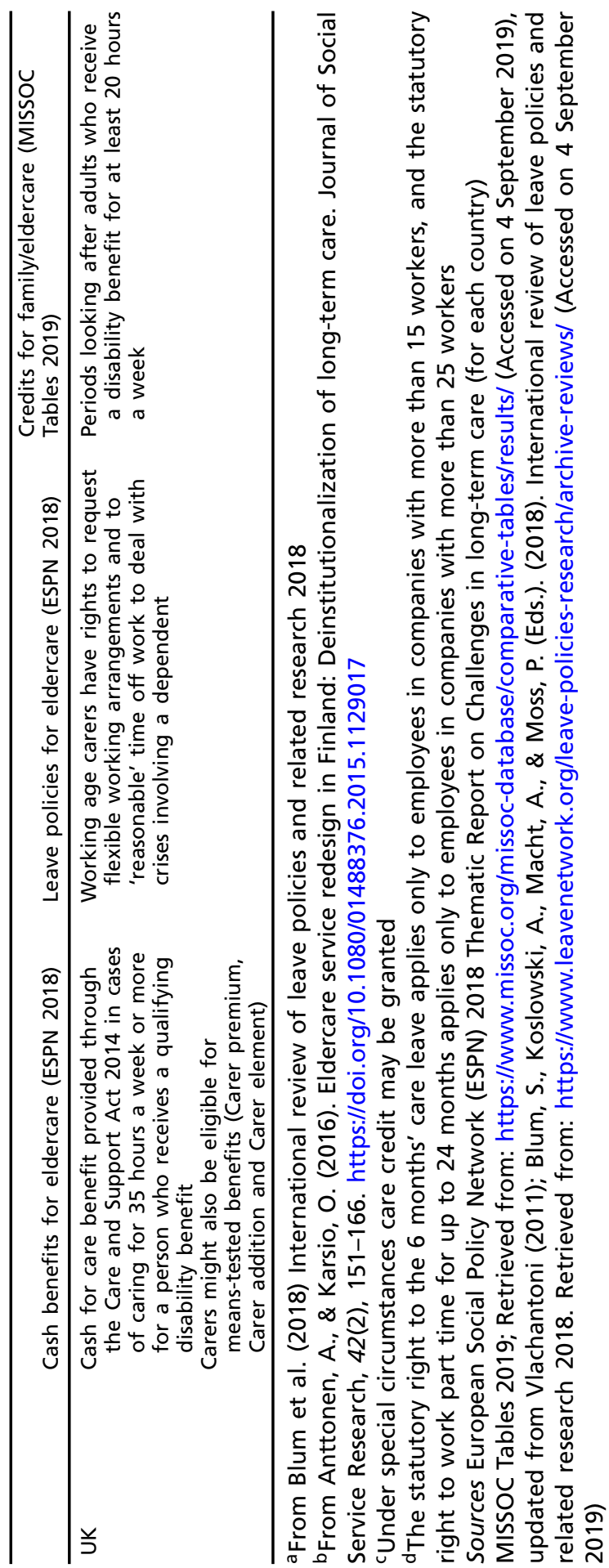

